\title{
Hypocretin-1 (orexin A) levels are normal in Huntington's disease
}

\author{
Baumann, Christian R ; Hersberger, Martin ; Bassetti, Claudio L
}

DOI: https://doi.org/10.1007/s00415-006-0146-7

Posted at the Zurich Open Repository and Archive, University of Zurich ZORA URL: https://doi.org/10.5167/uzh-156135

Journal Article

Published Version

Originally published at:

Baumann, Christian R; Hersberger, Martin; Bassetti, Claudio L (2006). Hypocretin-1 (orexin A) levels are normal in Huntington's disease. Journal of Neurology, 253(9):1232-1233.

DOI: https://doi.org/10.1007/s00415-006-0146-7 


\author{
Christian R. Baumann \\ Martin Hersberger \\ Claudio L. Bassetti
}

\section{Hypocretin-1 (orexin A) levels are normal in Huntington's disease}

Received: 24 August 2005

Received in revised form: 9 January 2006

Accepted: 24 January 2006

Published online: 5 April 2006

Sirs: Sleep-wake disturbances are common in Huntington's disease (HD), and include disturbances of the sleep-wake cycle, insomnia/ disturbed night sleep with nocturnal awakenings, and more rarely excessive daytime sleepiness, and disturbed REM sleep [13]. Furthermore, alteration of nutrition status and energy balance (including weight loss and altered plasma concentrations of ghrelin and leptin) are common in HD $[4,5]$.

At the present time, there are no biochemical markers for the diagnosis of HD.

Hypocretins (orexins) are hypothalamic neuropeptides which are involved in the regulation of arousal, feeding behavior and energy expenditure (i.a. via

C.R. Baumann $(\bowtie) \cdot$ C.L. Bassetti

Department of Neurology

University Hospital

Frauenklinikstrasse 26

8091 Zurich, Switzerland

Tel.: +41/1 255-55 11

Fax: +41/1 255-43 80

E-Mail: christian.baumann@usz.ch

M. Hersberger

Institute of Clinical Chemistry

U University Hospital

Zurich, Switzerland interactions with ghrelin and leptin). In the sleep-wake disorder narcolepsy-cataplexy, which is associated with altered energy expenditure, cerebrospinal fluid (CSF) hypocretin-1 levels are decreased due to a loss of hypothalamic hypocretin neurons $[6,7]$. Petersen et al. recently reported a significant loss of hypocretin neurons and dramatically decreased CSF hypocretin-1 levels in the best studied rodent model of HD [8]. Furthermore, the authors observed a decrease of hypocretin-immunopositive neurons in the hypothalamus of five human HD patients. In our preliminary study, therefore, we intended to test whether CSF hypocretin-1 levels are decreased in human HD patients.

In seven genetically confirmed HD patients (mean age 51 years, range 35-74 five men), we assessed duration of disease (defined as time from onset of first symptom to lumbar puncture), body mass indices and sleep-wake disturbances by standardized sleep questionnaires (including Epworth Sleepiness Scale=ESS; available in six patients). CSF hypocretin-1 levels were determined in all patients in a single radioimmunoassay as previously described [9]. Levels were compared with those of controls without neurological or other sleep-wake disorders $(n=20)$, and with patients with other neurodegenerative disorders (Parkinson's disease, $n=6$, mean age 71 years; dementia with Lewy bodies, $n=9$, mean age 73 years; Alzheimer's disease, $n=7$, mean age 72 years).

In the HD patients, mean duration of disease was 4.1 years (range 1-10). Mean BMI was 26.3 (range 22-33). Four patients reported unintentional weight loss. Sleep-wake disorders were com- mon complaints, and included insomnia $(n=4)$, fragmented night sleep without daytime tiredness $(n=1)$, and REM sleep behavior disorder $(n=1)$. Excessive daytime sleepiness (defined as ESS score $>10$ ) was not reported (mean ESS score 6.3, range 4-8).

CSF hypocretin-1 levels were normal in all HD patients (mean $441 \mathrm{pg} / \mathrm{ml}$, range 326-583) (Fig. 1). Levels did not differ significantly from those of patients with Parkinson's disease $(487 \mathrm{pg} / \mathrm{ml}$, range $307-654 \mathrm{pg} / \mathrm{ml}$ ), dementia with Lewy bodies $(504 \mathrm{pg} / \mathrm{ml}$, range 382-667), and Alzheimer's disease $(474 \mathrm{pg} / \mathrm{ml}$, range 333564). There were no associations between the presence of sleepwake disorders, Epworth Sleepiness Scale, duration of the disease, body mass index, unintentional weight loss, and CSF hypocretin-1 levels.

We could not find a hypocretin neurotransmission deficiency - as assessed by determination of CSF hypocretin-1 levels - in human HD. However, Petersen et al. reported an approximate $27 \%$ loss of hypocretin neurons in human HD [8]. We think that this discrepancy may be due to quantitative effects: Gerashchenko and colleagues [10] found that an average loss of $14 \%$ of rodent hypocretin neurons was not followed by a decrease of CSF hypocretin levels. An average loss of $73 \%$, however, was associated with a significant $50 \%$ decline in CSF hypocretin levels. The authors assumed that surviving hypocretin neurons might compensate for hypocretin neuronal loss by increased hypocretin ligand production. Thus, interpreting Petersen's finding together with the observations of Gerashchenko, it is conceivable that CSF hypocretin-1 levels are normal in HD patients. 


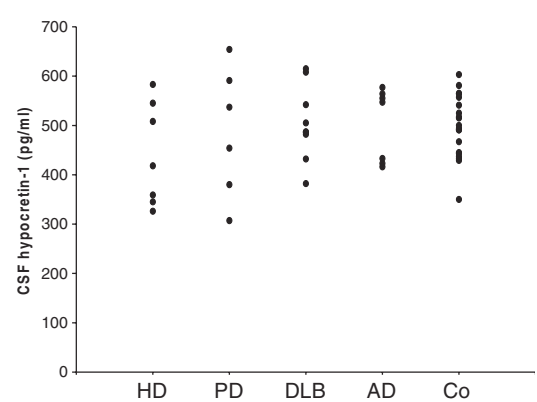

Fig. 1 CSF hypocretin-1 levels (in $\mathrm{pg} / \mathrm{ml}$ ) in Huntington's disease (HD, $n=7)$, Parkinson's disease (PD, $n=6)$, dementia with Lewy bodies (DLB, $n=9)$, Alzheimer's disease $(A D, n=7)$, and healthy controls $(\mathrm{Co}, \mathrm{n}=20)$

In conclusion, we found normal CSF hypocretin-1 levels in patients with Huntington's disease, independent of the presence of sleepwake disorders, and independent of nutritional status. CSF hypocretin-1 determination may not be helpful in the diagnosis of HD. Further studies to evaluate hypocretin neuronal loss in HD are required.

\section{References}

1. Starr A (1967) A disorder of rapid eye movements in Huntington's chorea. Brain 90:545-564

2. Brotini S, Gigli GL (2004) Epidemiology and clinical features of sleep disorders in extrapyramidal disease. Sleep Med 5:169-79

3. Wiegand M, Moller AA, Lauer CJ, Stolz S, Schreiber W, Dose M, Krieg JC (1991) Nocturnal sleep in Huntington's disease. J Neurol 238:203-208

4. Trejo A, Tarrats RM, Alonso ME, Boll MC, Ochoa A, Velasquez L (2004) Assessment of the nutrition status of patients with Huntington's disease. Nutrition 20:192-6

5. Popovic V, Svetel M, Djurovic M, Petrovic S, Doknic M, Pekic S, Miljic D, Milic N, Glodic J, Dieguez C, Casanueva FF, Kostic V (2004) Circulating and cerebrospinal fluid ghrelin and leptin: potential role in altered body weight in Huntington's disease. Eur J Endocrinol 151:451-5

6. Nishino S, Ripley B, Overeem S, Lammers GJ, Mignot E (2000) Hypocretin (orexin) deficiency in human narcolepsy. Lancet 355:39-40
7. Peyron C, Faraco J, Rogers W, Ripley B, Overeem S, Charnay Y, Nevsimalova S, Aldrich M, Reynolds D, Albin R, Li R, Hungs $M$, Pedrazzoli M, Padigaru M, Kucherlapati M, Fan J, Maki R, Lammers GJ, Bouras C, Kucherlapati R, Nishino S, Mignot E (2000) A mutation in a case of early onset narcolepsy and a generalized absence of hypocretin peptides in human narcoleptic brains. Nat Med 6:991-7

8. Petersen A, Gil J, Maat-Schieman ML, Bjorkqvist $\mathrm{M}$, Tanila $\mathrm{H}$, Araujo IM, Smith R, Popovic N, Wierup N, Norlen P, Li JY, Roos RA, Sundler F, Mulder H, Brundin P (2005) Orexin loss in Huntington's disease. Hum Mol Genet 14:39-47

9. Baumann CR, Dauvilliers Y, Mignot E, Bassetti CL (2004) Normal CSF hypocretin-1 (orexin A) levels in dementia with Lewy bodies associated with excessive daytime sleepiness. Eur Neurol 52:73-6

10. Gerashchenko D, Murillo-Rodriguez E, Lin L, Xu M, Hallett L, Nishino S, Mignot E, Shiromani PJ (2003) Relationship between CSF hypocretin levels and hypocretin neuronal loss. Exp Neurol 184:1010-6 